\title{
BMJ Open What influences patient satisfaction after total knee replacement? A qualitative long-term follow-up study
}

\author{
Nardia-Rose Klem (D) , ${ }^{1}$ Anne Smith (D) ,1,2 Peter O'Sullivan, ${ }^{1,2}$ \\ Michelle M Dowsey (D) , ${ }^{3}$ Robert Schütze, ${ }^{1,4}$ Peter Kent (D) , ${ }^{1,5}$ Peter FM Choong, ${ }^{3}$ \\ Samantha Bunzli (i) ${ }^{3}$
}

To cite: Klem N-R, Smith A, 0 'Sullivan $\mathrm{P}$, et al. What influences patient satisfaction after total knee replacement? A qualitative long-term follow-up study. BMJ Open 2021;11:e050385. doi:10.1136/ bmjopen-2021-050385

- Prepublication history for this paper is available online. To view these files, please visit the journal online (http://dx.doi org/10.1136/bmjopen-2021050385).

Received 18 February 2021 Accepted 01 November 2021

A) Check for updates

(C) Author(s) (or their employer(s)) 2021. Re-use permitted under CC BY-NC. No commercial re-use. See rights and permissions. Published by BMJ.

${ }^{1}$ School of Allied Health, Faculty of Health Sciences, Curtin University, Perth, Western Australia, Australia

${ }^{2}$ Enable Institute, Faculty of Health Sciences, Curtin University, Perth, Western Australia, Australia

${ }^{3}$ Department of Surgery, St Vincent's Hospital, Melbourne, Victoria, Australia

${ }^{4}$ Multidisciplinary Pain

Management Centre, Royal

Perth Hospital, Perth, Western

Australia, Australia

${ }^{5}$ Sports Science and Clinicial Biomechanics, University of Southern Denmark, Odense, Denmark

Correspondence to

Dr Nardia-Rose Klem;

nardia-rose.klem@curtin.edu.au

\section{ABSTRACT}

Objectives To explore whether a conceptual model of patient satisfaction previously developed $1-2$ years post-total knee replacement (TKR) is still relevant 3-4 years post-TKR. Specifically, (i) what is the stability in satisfaction levels 3-4 years post-TKR? and (ii) does the existing conceptual model of patient satisfaction after TKR apply at this later follow-up?

Design A constructivist grounded theory qualitative follow-up study. The present study was theoretically governed by the findings of the initial qualitative inquiry. One-on-one semi-structured interviews were used to test the assumptions of the model developed from the findings of the previous study.

Setting An urban Australian public hospital

Participants From 40 people who participated in the original study, 11 participants were purposively sampled based on their level of satisfaction and factors driving satisfaction as reported in their first interview. There were six women and five men, the average time since TKR was 3 years and 5 months, and the average age at time of interview was 77 years.

Results Satisfaction levels were mostly stable with the exception of three participants; two transitioned in a positive direction; one in a negative direction. The meaning of satisfaction and the factors that influenced satisfaction were consistent with the original findings. However, beliefs relating to the influence of ageing on persistent knee symptoms and functional limitations were more dominant in the present study.

Conclusions The findings provide support for patient satisfaction being a multifactorial construct that is potentially modifiable over time. Clinicians may apply the conceptual model we have described to optimise satisfaction in patients up to 3-4 years post-TKR.

\section{INTRODUCTION}

Measures of satisfaction are commonly used to capture patients' appraisal of the outcome of their total knee replacement (TKR) for knee osteoarthritis. A Delphi study by the Outcome Measures in Rheumatology initiative determined satisfaction to be a core outcome measure for TKR. ${ }^{1}$ However, despite the popularity and importance of measuring this construct, heterogeneity exists regarding
Strengths and limitations of this study

- A novel insight to the meaning and processes of satisfaction up to 4 years post-total knee replacement (TKR).

- Critical design involving reinterviewing of participants over 4 years post-TKR allowed for a thorough assessment of satisfaction over time.

- Consistent interviewer from the baseline study to this study facilitated the trust of the participants and therefore rich descriptions and insights.

- Sampling was restricted to the participants from the initial study, where broader sampling may have elicited different dimensions of satisfaction.

- Sampling was from a single institution where TKRs are government funded procedures, other settings may have yielded different aspects of satisfaction.

both the types of questions used and the quantification methods employed. ${ }^{2}$ Furthermore, two recent systematic reviews identified the poor content validity of current tools used to measure satisfaction after TKR and in musculoskeletal primary care settings, as the patients' voice in development of these measurement tools was absent. ${ }^{3}{ }^{4}$ Consequently, researchers and clinicians cannot be certain as to the meaning of patient responses to current satisfaction questionnaires.

Poor content validity has likely arisen due to lack of theoretical grounding surrounding this construct. ${ }^{5}$ To address this, our previous research sought to investigate what satisfaction meant to patients, and what factors and processes influenced their satisfaction levels after TKR. ${ }^{6}$ Using a constructivist grounded theory methodology, ${ }^{7}$ a conceptual model of satisfaction after TKR was developed. Satisfaction was found to mean different things to different people. Those that reported high levels of satisfaction described satisfaction as an improvement from their previous state. 


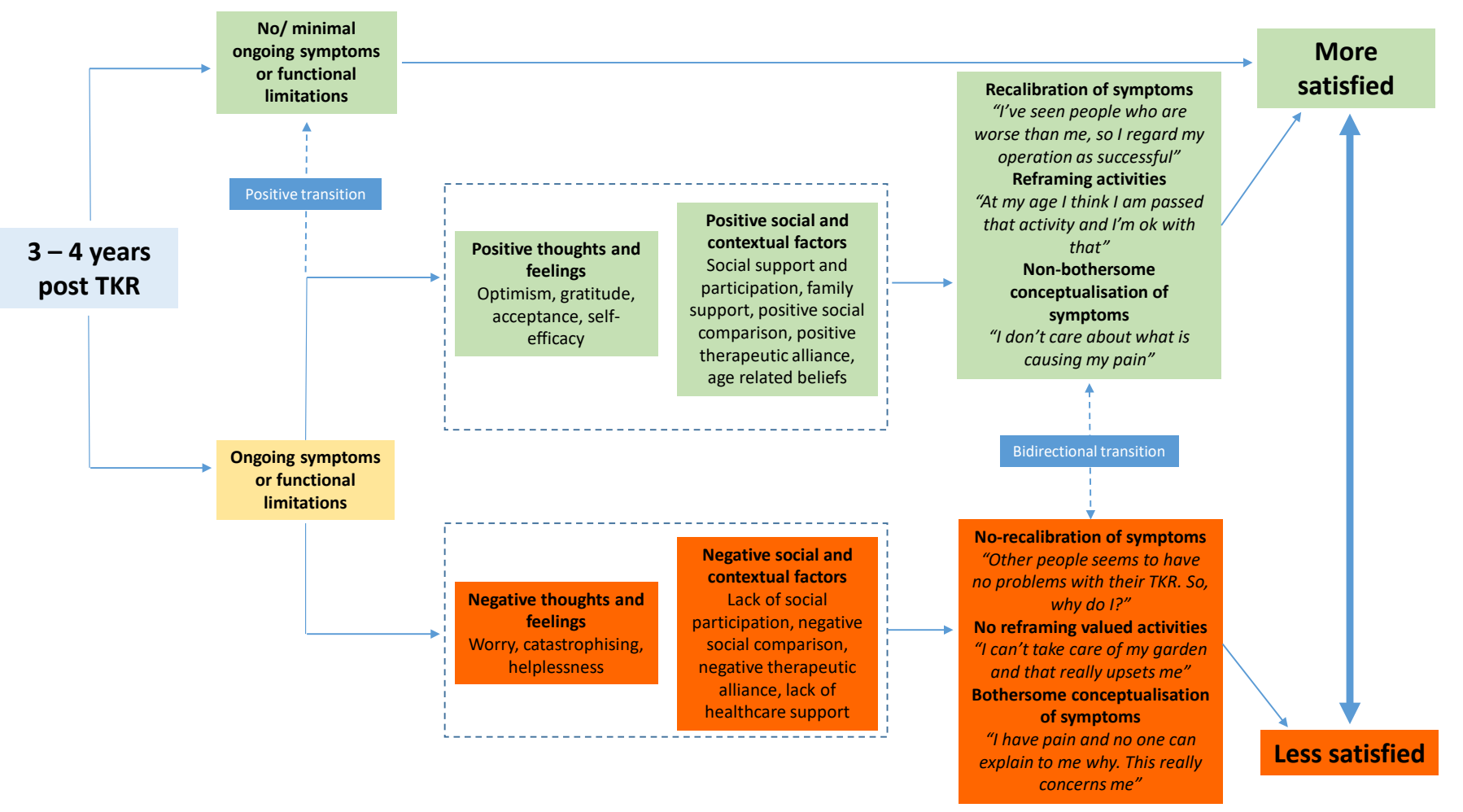

Figure 1 Conceptual model of patient satisfaction post-TKR. TKR, total knee replacement.

On the other hand, those that reported low levels of satisfaction believed satisfaction meant a resolution in pain and restoration in functional limitations. Our conceptual model (figure 1) described three pathways to satisfaction; (i) the 'full glass' who reported a high level of satisfaction with no/minimal ongoing symptoms or functional limitations; (ii) the 'glass half full' who reported high satisfaction and ongoing symptoms or functional limitations and (iii) the 'glass half empty' who reported low satisfaction and ongoing symptoms or functional limitations. For the latter two pathways, levels of satisfaction were influenced by three key mechanisms (recalibration of symptoms, reframing of valued activities and conceptualisation of symptoms) which interacted with thoughts, feelings, social and contextual factors on the pathway to high or low satisfaction. Those findings informed suggested avenues for clinicians to facilitate patients to experience greater satisfaction. ${ }^{6}$

Given our previous study was conducted in the first 2 years following TKR, interviewing the same participants 2 years later could provide insights into the stability of patient satisfaction over time, and whether the processes of the existing conceptual model are still valid. Such insights would help clinicians understand what drives high patient satisfaction levels in the longer term after TKR. Therefore, the research questions of this follow-up study were; (i) what is the stability in satisfaction 2 years following the initial inquiry? and (ii) does the existing conceptual model of patient satisfaction after TKR apply at this later follow-up?

\section{METHODS}

The original purposive sampling strategy can be found in our previous publication. ${ }^{6}$ In the initial (baseline) study, each participant was categorised into one of three satisfaction pathways (full glass, glass half full, glass half empty) and the key mechanisms influencing their reported level of satisfaction were identified. The satisfaction pathways were based on the accounts of people up to 2 years post-TKR with a range of pain and function outcomes, satisfaction scores, ethnic backgrounds, ages and a mix of men and women. Baseline data were analysed according to constructivist grounded theory, which is a methodological approach that facilitates an iterative, in-depth analysis of data. A key finding from this baseline study was that in the presence of ongoing symptoms and/or functional limitations, participants could reach high (glass half full) or low (glass half empty) satisfaction through the presence or absence of an adaption process through three key mechanisms: recalibration, reprioritisation and reconceptualisation of symptoms. These three key mechanisms were influenced by social and contextual factors (such as social support, relationship with healthcare professionals, living environment and social engagement), as well as thoughts and feelings (such as the presence of worry, fear, catastrophising and pain cause belief). For a full description of the methodology employed to generate this theory of satisfaction, see Klem et al. ${ }^{6}$

In the follow-up study, we selected participants 2 years after the baseline interview based on their satisfaction pathway and mechanisms identified from the previous study, ensuring that the different pathways and 
mechanisms were represented in our follow-up sample (see figure 1). The identified participants were considered our 'key informants', where the aim of this purposive sampling was to challenge rather than confirm the conceptual model. An exclusion criterion of this follow-up study was a subsequently developed cognitive impairment that prevented participants from providing meaningful responses to the interview questions.

Consistent with the qualitative approach, data collection and analysis occurred concurrently to enable emerging patterns in the data to be tested in subsequent interviews. Sampling ceased when diversity from our original sample was achieved; that is, all facets of the original conceptual model were feasibly tested, which in the context of this study was considered theoretical saturation. ${ }^{8}$ Theoretical saturation is a concept derived from grounded theory research, which does not subscribe to notions of repeated data. ${ }^{7}$ Instead, theoretical saturation looks for theoretical concepts and ceases data collection when all theoretical avenues have been sufficiently explicated. ${ }^{7}$ As this study was based on the theoretical framework of satisfaction from our baseline study, ${ }^{6}$ sampling in this present study aimed to represent the diversity of the original conceptual model and to 'test' this theory.

Each individual selected for follow-up was contacted via telephone. If they were interested in participating, a participant information sheet was emailed or mailed to them. The lead author contacted them within 3 days to confirm they had read and understood the information sheet, and consented to be interviewed. All interviews were conducted via telephone because the lead author was based in a different city to the participants. Interviews were conducted by the lead author (NK) who is a woman clinical physiotherapist, a $\mathrm{PhD}$ candidate with previous qualitative research experience, and who received training from a qualitative expert $(\mathrm{SB})$. NK had previously interviewed each of these participants for the baseline study 2 years prior, however, no other form of relationship existed between the lead author and the participants.

Prior to the commencement of the interviews, the lead author (NK) familiarised herself with each of the baseline transcripts of the participants. This involved taking notes on how their level of satisfaction related to the existing conceptual model, in particular, which mechanisms were most influential for them. Further, it was noted how social and contextual factors, and thoughts and feelings played a role in the three mechanisms. At the beginning of each interview, NK explained the purpose of the research and encouraged the participants to openly share their experiences. Anonymity and complete confidentiality was emphasised, in particular from their treating surgeon.

The interview schedule (table 1) was designed to test the stability of participants' satisfaction levels and the extent to which the original conceptual model (figure 1) remained relevant, while remaining flexible to explore new concepts not captured in the original model, if they emerged. Interviews lasted around $40 \mathrm{~min}$ on average, and were audio recorded and transcribed prior to analysis.

Data analysis followed the methodology of the previous qualitative study, which employed constructivist grounded theory. ${ }^{7}$ Under a constructivist grounded theory approach, researchers seek to understand patterns and processes in the data, rather than offer descriptions. ${ }^{7}$ The prior knowledge of the researchers is acknowledged and valued in the analysis, while the researchers simultaneously reflexively engage with the data to ensure the participants' perspectives are prioritised. ${ }^{7}$ Under this constructivist approach, participants' construction of satisfaction was central to the analysis. ${ }^{7}$ The analysis also adopted a critical lens in this follow-up study, whereby the aim of the analysis was to challenge rather than confirm the model from the baseline study. This was facilitated by discussion with the multidisciplinary authorship team in

\begin{tabular}{ll}
\hline Table 1 & Methods of analysis \\
\hline Stage & Description \\
\hline i & Familiarisation of transcripts, through reading and re-reading the data \\
ii & $\begin{array}{l}\text { Reflexive and analytic memo writing, whereby the lead author (NK) critically engaged her perception of the findings by } \\
\text { writing and reflecting on these, as well as reflecting on the analytic process }\end{array}$ \\
iii & $\begin{array}{l}\text { Coding the transcripts, guided by the initial memos produced, and by asking 'what is influencing this person's level of } \\
\text { satisfaction?' and 'how does the original conceptual model relate to this person's experience of satisfaction?'. At this } \\
\text { stage, initial thoughts of the data were presented to members of the multidisciplinary authorship team for discussion } \\
\text { and feedback, which included clinical and research physiotherapists, an orthopaedic research nurse, and a qualitative } \\
\text { expert }\end{array}$ \\
& $\begin{array}{l}\text { To refine the codebook from stage iii, two randomly selected transcripts were coded by AS to explore concordances } \\
\text { and disagreements }\end{array}$ \\
iv & $\begin{array}{l}\text { Further memo writing following coding, and summarising the key findings of the participants, which required the lead } \\
\text { author to compare the open coding findings with her original memos to create richer descriptions of the data }\end{array}$ \\
v & $\begin{array}{l}\text { The findings were compared with the existing conceptual model of patient satisfaction after TKR, which was again } \\
\text { presented to the multidisciplinary authorship team for discussion and refinement }\end{array}$ \\
vi &
\end{tabular}

TKR, total knee replacement. 
which alternative interpretations were sought and considered. The purposive sampling approach also facilitated this by targeting all aspects of the conceptual model.

Data were managed using Microsoft Word (Microsoft Corp) as the lead author's preference. For the present study, analysis was conducted in several stages, which were guided by the recommendations of Charmaz ${ }^{7}$ (table 2). Coding was conducted by NK and AS, where a combination of deductive codes, based on the conceptual model, and inductive codes looking at change over time were used. The analytic process was iterative, whereby, the lead author would move back and forth between the steps to ensure constant comparison between the new data and the findings of the existing model of patient satisfaction after TKR.

\section{Patient and public involvement}

In qualitatively exploring patient satisfaction after TKR, we are allowing patients to voice their priorities, experiences and preferences related to their TKR journeys. However, involvement of patients and the public in the research design or recruitment process was not feasible for this present study. Findings will be disseminated to participants once published.

\section{RESULTS}

\section{Participants}

Eleven of the 14 people identified as key informants from the baseline study of 40 participants, participated in the study. Among the three key informants who did not participate, one had developed cognitive impairment, one did not want to participate in the follow-up study, and one was unavailable for interview. Recruitment was ceased at 11 participants as sufficient diversity was captured to test the conceptual model. The demographic information for all participants, including their level of satisfaction and key mechanisms influencing their level of satisfaction as identified at the baseline interview, is presented in table 3 . There were six women and five men, the average time since TKR was 3 years and 5 months, and the average age at time of interview was 77 years.

Participant identification numbers are presented as the participant's identification number from the previous study followed by the letter 'B', to facilitate comparison with the previous publication. ${ }^{6}$

\section{Do satisfaction levels change at later follow-up?}

Overall, participants reported similar levels of satisfaction as the previous study, with the exception of three participants; P43b transitioned from 'glass half full' to 'full glass'; P04b transitioned from 'glass half empty' to 'glass half full' and P12B transitioned from 'glass half full' to 'glass half empty'. In the following quote, P12B acknowledges that her satisfaction levels have changed and attributes this lower level of satisfaction to her recent falls:

Interviewer: ... when I called you two years ago about your knee replacement, you told me that you were somewhat satisfied with your ability to do home and yard work. What do you think has changed?

12B: 'Yeah, well that was before I had the falls.

These transitions were aligned with the mechanisms identified in the baseline interviews, thus, no new themes emerged from interviewing these participants about their changed level of satisfaction.

\section{How does the existing conceptual model of patient satisfaction after TKR apply at this later follow-up?}

In the following section, participants who reported no or minimal ongoing symptoms or functional limitations, and high satisfaction in this follow-up study were classified as 'full glass'. Participants who reported ongoing symptoms and/or functional limitations were classified as either 'glass half full' (those that reported high satisfaction), or 'glass half empty' (those that reported low satisfaction) in this follow-up study. Where a participant changed classification from the baseline study, this has been described under their classification from the follow-up interviews; that is, their 'new' level of satisfaction.

\section{Full glass}

In alignment with the existing conceptual model, participants in the 'full glass' pathway at baseline continued to report no, or minimal ongoing symptoms or functional limitations in the follow-up interviews. Participants in this pathway also reported a stable level of symptoms; no participant reported any new or changed level of symptoms. As participant P14 explains, she perceived herself as lucky due to how positive her outcomes have been:

I'm one of the lucky ones obviously because I've never had problems. I've had both done and I've never had problems ... Now, yeah, it doesn't hurt but it's a very funny sensation when I go to kneel on them. But that is all, I can squat, I can do everything bar that

In the presence of minimal symptoms, the participants appeared to be more forthcoming with possible reasons for the occasional experience of pain compared with the baseline interviews. However, consistent with the previous enquiry, the pain itself and perceived reasons for pain, appeared non-bothersome. P1b who previously thought his occasional symptoms may be related to his age, explained how he experiences minimal, non-bothersome, pain as a result of ageing and changes to the weather, but he does not believe it negatively affects him:

It [the pain] doesn't affect me at all really. I just put it down to getting a bit old and change of weather. I get it in other parts of the body as well, I get in the elbow, ankle and the back.

Likewise, P16B who previously expressed contentment with not knowing the cause of his occasional pain, now described the effect of cold weather on his knee but felt like it was nothing to worry about: 
Table 2 Semi-structured interview schedule

\section{Construct from model}

Context

Overall outcome

Overall level of satisfaction // change

\section{Questions}

It's been a couple of years since we spoke, can you tell me how your TKR has been?

Overall, how satisfied are you with the results of your TKR?

(very satisfied, somewhat satisfied, somewhat dissatisfied, very dissatisfied) Why/why not?

If changed:

Last time we spoke you mentioned ___ about your satisfaction with can you think why this may have changed?

Symptoms // change // recalibration // Re-
conceptualisation
Can you tell me about any pain or other symptoms you currently experience?

Overall, how satisfied are you with the results of your TKR for improving your pain?

(very satisfied, somewhat satisfied, somewhat dissatisfied, very dissatisfied) Why/why not?

If changed:

Last time we spoke you mentioned ___ about your satisfaction with can you think why this may have changed?

Why do you think you are still having __ in your knee?

Why do you think you are no longer experiencing __ in your knee?

Function // change // Re-prioritisation

Can you tell me about any difficulties you have with activities at the moment?

Overall, how satisfied are you with the results of your TKR for improving your ability to do home and yard work?

(very satisfied, somewhat satisfied, somewhat dissatisfied, very

dissatisfied) Why/why not?

Overall, are you satisfied with the results of your TKR for improving your ability to do recreational activities?

(very satisfied, somewhat satisfied, somewhat dissatisfied, very dissatisfied) Why/why not?

Last time we spoke you mentioned about your satisfaction with can you think why this may have changed?

Can you tell me about how you have adapted/ not been able to adapt to the activities that you have difficulty with?

Conceptualisation of satisfaction

Can you help me understand, from your point of view, what it means to be very satisfied with your TKR?

Expectations

Can you try and cast your mind back and remember what you expected from your TKR? Do you believe these expectations have been met? Thinking forward, what are you now expecting from your TKR? Why? If changed:

Last time we spoke you said about your expectations for your TKR, what do you think about these expectations now? Do you believe they have been met?

\begin{tabular}{|c|c|}
\hline Social & $\begin{array}{l}\text { Thinking back through the time since you had your operation, can you tell } \\
\text { me about any family or friends who helped you along your journey? } \\
\text { Have you encountered many other people that have had a TKR? What did } \\
\text { you think about their outcomes/what did you learn from them? }\end{array}$ \\
\hline Cognitions & $\begin{array}{l}\text { What kind of mind set did you have along your TKR journey? } \\
\text { What do you think is important for having a successful outcome after TKR? }\end{array}$ \\
\hline
\end{tabular}


Table 3 Participant characteristics

\begin{tabular}{|c|c|c|c|}
\hline Participant & Characteristics & $\begin{array}{l}\text { Levels of satisfaction and } \\
\text { mechanisms from initial study }\end{array}$ & $\begin{array}{l}\text { Levels of satisfaction and } \\
\text { mechanisms at 2-year follow-up }\end{array}$ \\
\hline 01b & $\begin{array}{l}\text { Male } \\
3 \text { years } 10 \text { months post-TKR } \\
76 \text { years old }\end{array}$ & $\begin{array}{l}\text { Full glass } \\
\text { No/minimal on going symptoms or } \\
\text { functional limitations }\end{array}$ & $\begin{array}{l}\text { Full glass } \\
\text { No/minimal on going symptoms or } \\
\text { functional limitations }\end{array}$ \\
\hline $02 b$ & $\begin{array}{l}\text { Female } \\
3 \text { years } 8 \text { months post-TKR } \\
72 \text { years old }\end{array}$ & $\begin{array}{l}\text { Glass half full } \\
\text { Non-bothersome conceptualisation } \\
\text { of symptoms } \\
\text { Reframing valued activities }\end{array}$ & $\begin{array}{l}\text { Glass half full } \\
\text { Positive conceptualisation of } \\
\text { symptoms } \\
\text { Reframing valued activities }\end{array}$ \\
\hline $04 b$ & $\begin{array}{l}\text { Male } \\
3 \text { years } 9 \text { months post-TKR } \\
79 \text { years old }\end{array}$ & $\begin{array}{l}\text { Glass half empty } \\
\text { Inability to reframe valued activities }\end{array}$ & $\begin{array}{l}\text { Glass half full } \\
\text { Positive conceptualisation of } \\
\text { symptoms } \\
\text { Reframed valued activities }\end{array}$ \\
\hline $11 b$ & $\begin{array}{l}\text { Male } \\
3 \text { years } 5 \text { months post-TKR } \\
78 \text { years old }\end{array}$ & $\begin{array}{l}\text { Glass half full } \\
\text { Non-bothersome conceptualisation } \\
\text { of symptoms }\end{array}$ & $\begin{array}{l}\text { Glass half full } \\
\text { Positive conceptualisation of } \\
\text { symptoms } \\
\text { Reframed valued activities }\end{array}$ \\
\hline $14 b$ & $\begin{array}{l}\text { Female } \\
3 \text { years } 6 \text { months post-TKR } \\
71 \text { years old }\end{array}$ & $\begin{array}{l}\text { Full glass } \\
\text { No/minimal on going symptoms or } \\
\text { functional limitations }\end{array}$ & $\begin{array}{l}\text { Full glass } \\
\text { No/minimal on going symptoms or } \\
\text { functional limitations }\end{array}$ \\
\hline $16 b$ & $\begin{array}{l}\text { Male } \\
3 \text { years } 9 \text { months post-TKR } \\
70 \text { years old }\end{array}$ & $\begin{array}{l}\text { Full glass } \\
\text { No/minimal on going symptoms or } \\
\text { functional limitations }\end{array}$ & $\begin{array}{l}\text { Full glass } \\
\text { No/minimal on going symptoms or } \\
\text { functional limitations }\end{array}$ \\
\hline $18 b$ & $\begin{array}{l}\text { Female } \\
4 \text { years post-TKR } \\
82 \text { years old }\end{array}$ & $\begin{array}{l}\text { Glass half full } \\
\text { Reframing valued activities }\end{array}$ & $\begin{array}{l}\text { Glass half full } \\
\text { Positive conceptualisation of } \\
\text { symptoms }\end{array}$ \\
\hline $41 b$ & $\begin{array}{l}\text { Female } \\
2 \text { years } 8 \text { months post-TKR } \\
81 \text { years old }\end{array}$ & $\begin{array}{l}\text { Full glass } \\
\text { No/minimal on going symptoms or } \\
\text { functional limitations }\end{array}$ & $\begin{array}{l}\text { Full glass } \\
\text { No/minimal on going symptoms or } \\
\text { functional limitations }\end{array}$ \\
\hline $43 b$ & $\begin{array}{l}\text { Male } \\
2 \text { years } 8 \text { months post-TKR } \\
83 \text { years old }\end{array}$ & $\begin{array}{l}\text { Glass half full } \\
\text { Positive conceptualisation of } \\
\text { symptoms }\end{array}$ & $\begin{array}{l}\text { Full glass } \\
\text { No/minimal on going symptoms or } \\
\text { functional limitations }\end{array}$ \\
\hline
\end{tabular}

TKR, total knee replacement.

[pain in] the knees? No, no worries. Like I said they can ache a little bit type of thing but um, ah when it gets real cold but ah, no worries-but it's time to put on long trousers now and that keeps them warm

\section{Glass half full pathway}

Participants in the 'glass half full' pathway continued to conceptualise satisfaction as improvement from the preoperative state. As described by $\mathrm{P} 18 \mathrm{~b}$, she felt osteoarthritis was all through her body (including her knees) and very painful, so the TKR operation was a success:
Well [I'm satisfied] because-oh I don't know, because I have the, I had all through my legs-because I have osteoarthritis through the whole body, so my knees are-they're very sore, very bad, so ah, the operation was successful.

Additionally, P11b, who described continual difficulty walking and felt like the knee wasn't $100 \%$, reported high level of satisfaction based on a previously worse state:

Comparing to what it was, yeah, absolutely satisfied, yeah. 
The mechanisms that facilitated satisfaction in the presence of ongoing symptoms or functional limitations were consistent with the existing conceptual model; recalibration, reframing valued activities and non-bothersome conceptualisation of symptoms (figure 1). However, it was apparent the mechanisms that influenced high levels of satisfaction for an individual could change over time. For P11b, his satisfaction was previously due to conceptualising his symptoms as continually improving. However, in the follow-up interview, he developed a non-bothersome conceptualisation of his symptoms through believing his symptoms were good for his age:

At my age it doesn't matter. I just walk and do everything to my knee. I don't walk if I have a lift or whatever or go anywhere out of the way. I just carry on the way I do, I'm 78 so I think I get around pretty good really for that age. ... I'm just a little bit disappointed in it, but I've got to remember I'm nearly 80 , so I suppose I have to be satisfied with it, wouldn't I?

Additionally, the role of social comparison to facilitate recalibration of symptoms was also present for $\mathrm{P} 11 \mathrm{~b}$, who compared himself to others he perceived were doing worse than him:

Yeah, well, I've heard a lot of complaints about it. There's a lot of people that are not as good as me, that I know, though, and so, I don't worry about mine. I've seen [surgeon] the other day and they $\mathrm{x}$ rayed me and said everything was in place, so I feel good about that too.

Similarly, for P18b, in her baseline interview, described reframing valued activities in the form of setting small functional targets, such as gradually increasing time on her stationary bike. In the follow-up interview, her mechanisms for satisfaction were modified such that she appeared to conceptualise her impaired function as due to her other comorbidities, particularly her spine. Although the influence of comorbidities was apparent in her previous interview, the attribution of these to her reason for being satisfied came across more strongly in the follow-up interview:

Walking, that relates to my spine, it has nothing to do with my knees. I can't reach my toes for instance, I have to have pedicures because I can't reach my toes there, I can't bend down but that has nothing to do with my knees. That is my back so that's hard for me to distinguish you know, what I'm saying?

Participant $\mathrm{P} 04 \mathrm{~b}$, who transitioned into this group from 'glass half empty', appeared to reframe activities based on what he considered to be reasonable for his age, and this reframing was a key mechanism for transitioning to becoming satisfied. In the baseline interview, P04b reported dissatisfaction due to an inability to do valued activities such as golf. In the follow-up interview P04b describes what he has decided as appropriate for his age:
P04b: I probably after I spoke to you, if that was 2 years ago um, I probably did start playing again with a friend of mine, ah, yeah, ah and we used to just play 9 holes we'd get a cart and we'd play probably once a week and um, it got to the stage where ah, I couldn't I-I had to give it away because I couldn't walk that far-and once again, which I'm sure it was because of the other knee, I can't remember having any trouble with my right knee it was always the left knee and the hip so..."

NRK: Would you ever consider going back to it?

P04b: Nup. I figure at 80 I'm, I've passed it."

Consistent with the existing model, social and contextual factors, as well as thoughts and feelings were also influential in this pathway. In particular, the role of acceptance pertaining to age-related limitations appeared to play a larger role than in the previous study, as has been demonstrated in the previous quotes. In addition to this, consistent with the baseline study, a positive relationship with the surgeon who had performed their TKR appeared to be an important social and contextual factor for satisfaction, as explained by P18b:

Yes, ah, terrific man, um, well I suppose he was very caring and looking after me afterwards. I like him very much, he is very calming very friendly, very reassuring and I thought he knew what he was doing, if you know what I mean

Further, participants in this pathway generally did not express thoughts and feelings of worry and anxiety about their current symptoms. Participants explained an ability to manage doing what they wanted despite limitations. P11b expressed a lack of worry about his persistent knee clunking and adequate self-efficacy to 'work around it':

I'm not worried about it [knee clunking], no, not at this stage. I can manage it pretty good now, and so I work around it a little bit, yeah.

Likewise, P18b reported her knee instability as neither worrisome nor concerning, indicating a lack of distress related to her current symptoms or functional limitations:

If I'm standing long time ah, not that I'm walking, if I'm standing long time it sort of tends to sometimes give way on me, you know, but it's not-I'm not concerned and it's not really worrying, you know.

\section{Glass half empty}

Participants In the 'glass half empty' pathway continued to conceptualise satisfaction as complete resolution in symptoms and or functional impairments. In the follow-up interviews, 'glass half empty' participants expressed a stronger emphasis on satisfaction as meaning having a knee that felt and moved like a 'normal' knee:

[being very satisfied] ... means I'll be able to walk normally without any aids or anything or any frames 
or anything that I have to use and that's it ... as if I hadn't had any operations at all [P39b]

The three key mechanisms identified in the baseline study appeared to remain influential for 'glass half empty' participants in the follow-up study. For participant P39b, whose low level of satisfaction remained the same from the previous enquiry, her previous mechanism of a negative conceptualisation of symptoms was confirmed and strengthened; P39b underwent a revision surgery to try and address her persistent pain after her initial TKR, only to continue experiencing pain. P39b explained how she understood the cause of her symptoms:

I was in too much pain after the surgery and the way the knee was going back it was really giving me a lot of pain, and that because it was very hypo-extending back ... somehow it was stretched or something he said that they had it stretched or whatever they did. And they had to do it again, but by fixing it I think he might of, maybe, I think he might have put too much padding in. You know packed it up too much this time. Maybe, I don't know, I hope I don't have to go under again and take some of that padding off to stop that nerve. That's probably why it's pressing on the nerve now.

Additionally, due to social comparison with others who had undergone TKR and had a positive outcome, P39b recalibrated her symptoms as worse than theirs. This comparison also contributed to further confusion regarding her conceptualisation of symptoms:

She was good and she had the second one done and she's ok. There's nothing wrong with her so you know, I don't know ... And she's quite happy and she's walking as if she never ever had anything done, you know like, nothing is ever-she never even had the operations and she's fit and goes for walks and does you know, exercises and goes to the gym and all and you know, she's quite happy with it. And I'm thinking, well if you can do that well how come mine is like that, why am I having all this problems, you know

Participant P12b, who transitioned from 'glass half full' to 'glass half empty', experienced two falls in the period since her baseline interview. Although she reported persistent symptoms in her baseline interview, at the follow-up interview she believed her pain was due to the falls. However, she reported that her doctor assured her there was nothing internally wrong with her knee and dismissed her concerns about her pain. This appeared to lead to an inability to have a positive conceptualisation of her symptoms, and subsequent reports of low levels of satisfaction:

Since I've had the fall, yes. I don't think I had very much pain at all, before I had the fall. I had to go over to [location] to have me leg x-rayed, because I had me shoulders x-rayed as well. And he said, "There's no need to do the right one". He x-rayed the left leg, but he didn't do the right one, that I had replaced. And he said, "Everything there should be fine". So, okay. And that was it ... I've told him several times that I've got pain in the knee, and so he just makes jokes; he says, "You been playing football, have you?" I say, "Oh yeah, of course".

P12b further described how she was unable to do valued activities, which also contributed to her low level of satisfaction:

Very dissatisfied. I used to be able to look after my own garden, but now I've got to pay a fellow $\$ 60$ a fortnight to come and cut my lawn ... That's how bad things are, and I've got a mower, and a blower down in the shed, and rakes and what have you, but I can't use them.

Consistent with the existing model, the influence of social and contextual factors, as well as thoughts and feelings, appeared to play a role in this pathway. P39b recalls feeling unheard by her surgeon and feeling high levels of frustrations because of this. P39b told a story of how her surgeon did not believe her problems with walking until a chance encounter on the street:

... He was in the street talking to another guy. And then I went past him, and said hello and I kept passing ... he saw me and then he realised what I was talking about. And I thought well I've been trying to tell you that 12 months ago. Which I was really, really got upset about it, but it was, you know, could've done it 12 months before and wouldn't have had all that problem ... all the things I had to do and then he was thinking of getting me-oh what was it? Like bars and that put on to keep me leg straight and oh look, all the things that he was trying to do and didn't need to do any of that. Which annoyed me really, really bad because, you know, back and forward and living in [location] into Melbourne all the time, which you know, all that time which you didn't sort of-and I tried to tell him what was going on and he just didn't-I don't know whether he wasn't listening or he wasn't-I don't know what it was. Until he saw me walk and then he said, "Oh, I realise what you're talking about" oh it's about time.

For P12b, her low level of satisfaction was also influenced by the contextual factor of a negative relationship with healthcare professions, as demonstrated in the previous quote where her reports of pain following her falls were dismissed. Additionally, the experience of falls contributed to negative thoughts and feelings, particularly high levels of fear related to her knee:

And that's very frightening, so unless I've got somebody with me, I try not to go there. I go over to the plaza if I have to have my eyes tested or something, get new glasses. But otherwise, I stay away from there. 


\section{DISCUSSION}

The findings from this qualitative follow-up study contribute to understanding the processes involved in patient satisfaction 3-4 years after TKR. This study was conducted 2 years following the baseline enquiry and demonstrated how the three pathways to high and low satisfaction were still relevant ('full glass', 'glass half full' and 'glass half empty'), as were the originally identified mechanisms of these pathways (recalibration, reframing valued activities and conceptualisation of symptoms). However, participants could change their level of satisfaction or the key mechanism(s) driving their level of satisfaction over the 2 years following the baseline study. This highlights that both the levels of satisfaction and the reasons underpinning it are fluid over time. Furthermore, the factors underpinning these changes are potentially modifiable with targeted intervention.

This follow-up study provides novel insight to patient satisfaction as a continually changing process up to 4 years post-TKR. Whether satisfaction changes over time after TKR, and if so how and why, has not been previously investigated. The findings from the present study indicate that patient satisfaction may be better considered as a 'moving target' due to the interaction of various psychosocial processes.

This fluidity observed in patient satisfaction suggests that clinicians should continue to monitor patient satisfaction for a number of years post-TKR. Despite the changeable nature of satisfaction seen in this study, participants did not indicate any belief that their outcomes could change without further surgery. This is in agreement with previous qualitative research that found patients believe they are 'stuck with' their TKR outcomes. ${ }^{9}$ Thus, it is important to inform patients their outcomes are potentially modifiable over time. Additionally, in alignment with our previous study ${ }^{6}$ and existing satisfaction literature ${ }^{510}$ the role of the surgeon in forging a positive therapeutic alliance was important in achieving high levels of satisfaction. This appeared to promote trust in the quality of the TKR surgery and belief of a good outcome despite continued symptoms and functional limitations. Thus, positive communication techniques and relationship building, such as active listening and validating concerns regarding the integrity of the TKR, may be important in assisting patient to achieve high levels of satisfaction. Furthermore, understanding the specific basis for a person's dissatisfaction, using the proposed conceptual model, may allow for targeted management to assist patients to feel more satisfied up to 4 years post-TKR.

The influence of the three key mechanisms in pathways to high and low levels of satisfaction suggest patient satisfaction is largely a function of patient adaptability. This is aligned with previous qualitative research that found patients post-TKR expressed happiness with their TKR and described their outcomes as good despite continued pain or an inability to do valued activities. ${ }^{11}$ The potential of patients to arrive at a positive appraisal of their TKR outcomes despite ongoing pain and/or functional limitations is an important consideration when interpreting scores on measures of patient satisfaction; high levels of satisfaction may not necessarily reflect meaningful improvement in pain and function.

This follow-up study importantly revealed the more dominant influence of negative age-related beliefs on symptoms and functional limitations compared with the baseline study. This is consistent with other qualitative and quantitative research that has found older people more readily accept that the process of ageing relates to functional decline and persistent pain. ${ }^{912}$ Despite these beliefs positively influencing a non-bothersome conceptualisation of symptoms and resultant reports of high satisfaction in this study, it may promote continual disengagement from valued life activities in this cohort. For example, participant 04b stopped playing golf, which has social, cognitive and physical health benefits. The negative age-related beliefs seen in this study may reflect a stronger social narrative of age-related prejudice, which has become internalised in older adults. ${ }^{13} 14$ Clinicians may play an important role in addressing internal negative self-perceptions of ageing in patients to prevent adverse health and well-being outcomes. ${ }^{14-16}$

\section{Clinical implications}

As the findings from this study indicate that patient satisfaction is a continuous journey up to 4 years post-TKR, it may be appropriate to support vulnerable patients over this period of time. As orthopaedic surgeons may not always follow their patients beyond the first year or two post-TKR, general practitioners and physiotherapists may be best positioned to provide care at this stage, with referral on to other appropriate allied health as required. To assist clinicians, we propose a road map (figure 2) detailing the utilisation of the conceptual model to identify key barriers to satisfaction and potential treatment pathways for individualised management, for patients with low satisfaction up to 4 years post-TKR. In alignment with clinical guidelines, ${ }^{17}$ this ongoing support should include continuous monitoring in the form of screening tools such as the WOMAC for pain and function, ${ }^{18}$ and the Örebro or STarT Back for psychological factors. ${ }^{19} 20$ Screening tools can guide patient-centred communication, the importance of which was further highlighted in this study. The findings suggest that patients reporting low levels of satisfaction require validating and reassuring communication techniques, and a strong therapeutic alliance to facilitate an improvement in satisfaction levels. Our previous publication provides exemplar communication techniques to assist patients who report low levels of satisfaction. ${ }^{6}$ The identification of both physical and psychosocial barriers to achieving high satisfaction highlights the potential role of physiotherapy and psychological support in this process. The over-attribution of the perceived effects of ageing on persistent symptoms and functional limitations in this study suggest clinicians may play and important role in educating patients of the potential to improve their clinical outcomes. This can 


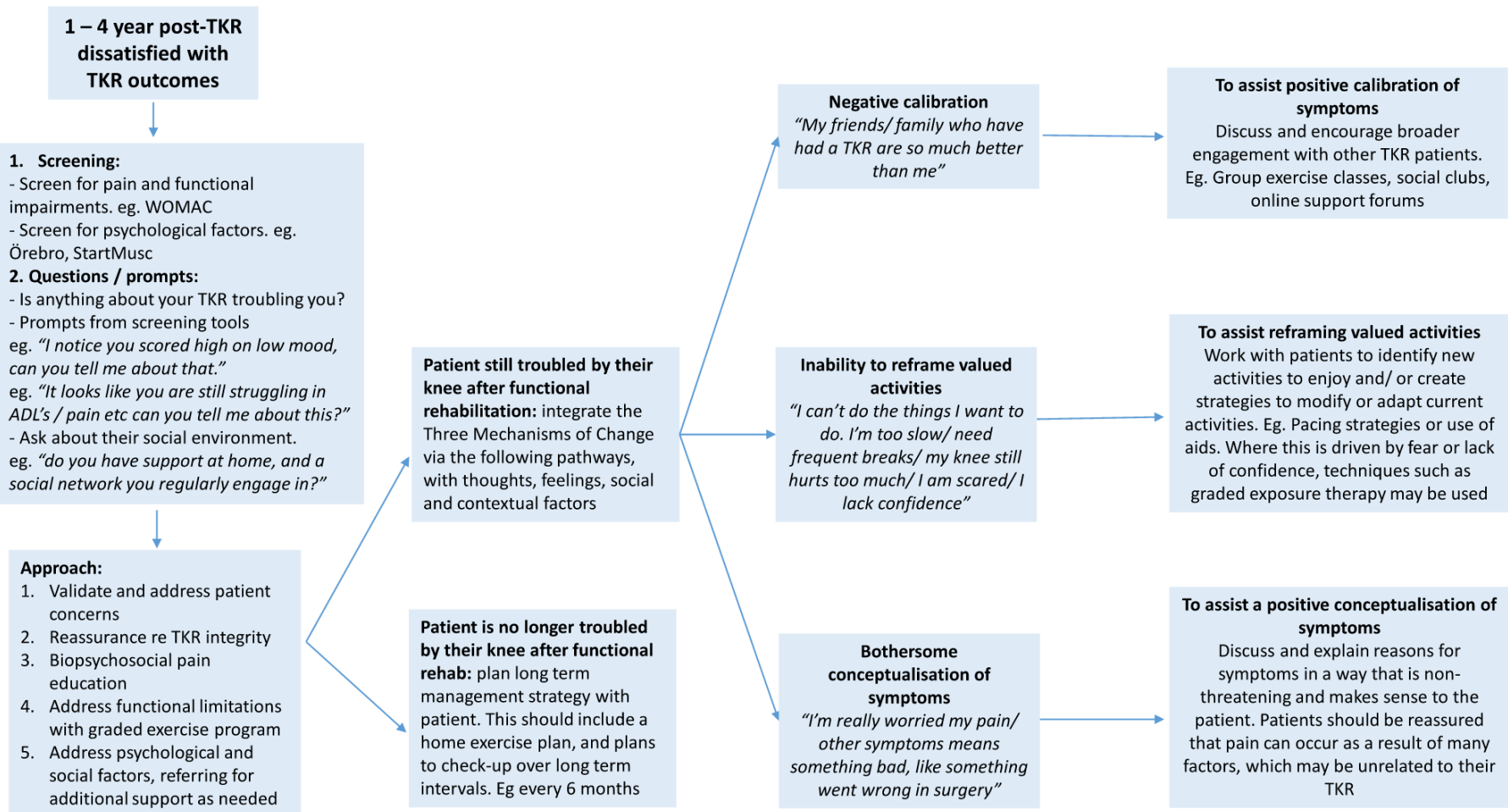

Figure 2 Roadmap to improve satisfaction levels post-TKR. TKR, total knee replacement.

include addressing implicit, negative age-related beliefs and working with patients to set realistic functional goals, or targets to improve social participation. ${ }^{15}$ Rehabilitation that disconfirms negative age-related beliefs, such as helping people to develop movement strategies that are non-provocative, may provide successful experiences that encourage further engagement with valued life activities. Future research may be concerned with testing the framework proposed in this research for providing targeted care for those who remain dissatisfied post-TKR.

\section{Strengths and limitations}

To achieve a longitudinal understanding of patient satisfaction, we were required to sample from the participants in our previous study. This may have limited the scope of our findings and participants of a younger age or at longer follow-up may have identified additional factors influential to satisfaction. As no participant classified as 'full glass' reported any different or new symptoms, it is unknown if they would remain satisfied if they had developed bothersome symptoms. The sample was from a single site, an Australian public hospital, where TKRs are government funded procedures. Thus, the experiences may reflect the aspects of care which do not transfer to other health settings.

Using a longitudinal qualitative design by reinterviewing key informant participants from the baseline study sample allowed a novel, in-depth comparison and analysis of factors related to what satisfaction means to patients, and how and why satisfaction level changes or remain the same over time. Additionally, a consistent interviewer across the baseline and follow-up studies facilitates a trusting relationship with the participants and can yield more rich descriptions in the interviews. This also meant the interviewer was familiar with the participants' experiences, and thus was able to compare and contrast meaning over time. This is important when documenting contextual cues, such as mood, which may not be revealed in written transcripts.

\section{CONCLUSIONS}

The findings from the present study provide support for satisfaction with TKR being a multifactorial construct which is influenced by potentially modifiable factors that can vary over time. The results of this study also demonstrate how satisfaction after TKR can be fluid in the level of satisfaction and the factors underpinning the level of satisfaction. The findings suggest avenues for clinicians to assist their patients to feel satisfied with their TKR outcomes up to 4 years postsurgery, and highlight the importance of informing TKR patients to present for care in order to optimise their TKR outcomes, rather than accepting ongoing symptoms or functional limitations.

Acknowledgements The publication of this work was supported by Physiotherapy Research Foundation grant number T16-CR008. The Physiotherapy Research Foundation had no role in the conduct of this study.

Contributors NRK is the guarantor of this manuscrpit and accepts repsonsibility for the overall content. NRK, AS, SB developed the concept for the study. NRK, AS, $\mathrm{SB}, \mathrm{PO}, \mathrm{RS}, \mathrm{PK}, \mathrm{PFMC}, \mathrm{MMD}$ contributed to the planning, reporting and design of the study. NRK acquired the data. NRK, AS, SB, PO, RS, PK, PFMC, MMD contributed to the analysis and interpretation of data. NRK drafted the manuscript. NRK, AS, SB, PO, RS, PK, PFMC, MMD contributed to and approved the final version submitted. 
Funding This work was supported by an Australian National Health and Medical Research Council Centre of Research Excellence in Joint Replacement Surgery (APP1116325). The funders had no role in the conduct of this study.

Competing interests PFMC reports grants from National Health \& Medical Research Council, during the conduct of the study; personal fees from Stryker, personal fees from Johnson \& Johnson, grants from Medacta, personal fees from Kluwer, outside the submitted work. PFMC is supported by a National Health \& Medical Research Council Practitioner Fellowship (APP1154203). PO reports grants from National Health \& Medical Research Council, during the conduct of the study. MMD reports grants from Medacta International, grants from National Health \& Medical Research Council, grants from Australian Research Council, personal fees from Pfizer, outside the submitted work; MMD is supported by a National Health \& Medical Research Council Career Development Fellowship (APP1122526) and a Dame Kate Campbell Fellowship. AS reports grants from National Health \& Medical Research Council, during the conduct of the study. PK, or any member of his immediate family, has no funding or commercial associations (eg, consultancies, stock ownership, equity interest, patent/licensing arrangements, etc) that might pose a conflict of interest in connection with the submitted article. I agree and confirm this statement as true. SB, or any member of her immediate family, has no funding or commercial associations (eg, consultancies, stock ownership, equity interest, patent/licensing arrangements, etc) that might pose a conflict of interest in connection with the submitted article. I agree and confirm this statement as true. RS, or any member of his immediate family, has no funding or commercial associations (eg, consultancies, stock ownership, equity interest, patent/licensing arrangements, etc) that might pose a conflict of interest in connection with the submitted article. I agree and confirm this statement as true. NK, or any member of her immediate family, has no funding or commercial associations (eg, consultancies, stock ownership, equity interest, patent/licensing arrangements, etc) that might pose a conflict of interest in connection with the submitted article.

Patient and public involvement Patients and/or the public were not involved in the design, or conduct, or reporting, or dissemination plans of this research.

Patient consent for publication Not required.

Ethics approval This study has been conducted in accordance with the ethical standards in the 1964 Declaration of Helsinki. Ethics approval was granted by St Vincent's Hospital (Melbourne) Human Research Ethics Committee (HREC/17/ SVHM/251).

Provenance and peer review Not commissioned; externally peer reviewed.

Data availability statement All data relevant to the study are included in the article or uploaded as supplementary information. All available data is included in this manuscript - what is in the article is correct.

Open access This is an open access article distributed in accordance with the Creative Commons Attribution Non Commercial (CC BY-NC 4.0) license, which permits others to distribute, remix, adapt, build upon this work non-commercially, and license their derivative works on different terms, provided the original work is properly cited, appropriate credit is given, any changes made indicated, and the use is non-commercial. See: http://creativecommons.org/licenses/by-nc/4.0/.

\section{ORCID iDs}

Nardia-Rose Klem http://orcid.org/0000-0002-4414-2719

Anne Smith http://orcid.org/0000-0002-4667-7389

Michelle M Dowsey http://orcid.org/0000-0002-9708-5308

Peter Kent http://orcid.org/0000-0002-2429-9233

Samantha Bunzli http://orcid.org/0000-0002-5747-9361

\section{REFERENCES}

1 Singh JA, Dowsey M, Choong PF. Patient endorsement of the outcome measures in rheumatology (OMERACT) total joint replacement (TJR) clinical trial draft core domain set. BMC Musculoskelet Disord 2017;18:111.

2 Kahlenberg CA, Nwachukwu BU, McLawhorn AS, et al. Patient satisfaction after total knee replacement: a systematic review. Hss $J$ 2018;14:192-201.

3 Klem N-R, Kent P, Smith A, et al. Satisfaction after total knee replacement for osteoarthritis is usually high, but what are we measuring? A systematic review. Osteoarthr Cartil Open 2020;2:100032.

4 Pellekooren S, Ostelo R, Pool A. Content validity of patient reported outcome measurement instruments for patient satisfaction in primary care: systematic review of studies involving patients with musculoskeletal complaints. J Orthop Sports Phys Ther 2021:51:94-102.

5 Batbaatar E, Dorjdagva J, Luvsannyam A, et al. Conceptualisation of patient satisfaction: a systematic narrative literature review. Perspect Public Health 2015;135:243-50.

6 Klem N-R, Smith A, O'Sullivan P, et al. What influences patient satisfaction after TKA? A qualitative investigation. Clin Orthop Relat Res 2020;478:1850-66.

7 Charmaz K. Constructing grounded theory: a practical guide through qualitative analysis. London: SAGE Publications, 2006.

8 Starks H, Trinidad SB. Choose your method: a comparison of phenomenology, discourse analysis, and grounded theory. Qual Health Res 2007;17:1372-80.

9 Jeffery AE, Wylde V, Blom AW, et al. "It's there and I'm stuck with it": patients' experiences of chronic pain following total knee replacement surgery. Arthritis Care Res 2011;63:286-92.

10 Sitzia J, Wood N. Patient satisfaction: a review of issues and concepts. Soc Sci Med 1997:45:1829-43.

11 Woolhead GM, Donovan JL, Dieppe PA. Outcomes of total knee replacement: a qualitative study. Rheumatology 2005;44:1032-7.

12 Robertson DA, Kenny RA. "I'm too old for that" - The association between negative perceptions of aging and disengagement in later life. Pers Individ Dif 2016;100:114-9.

13 WHO. Ageing: Ageism [Internet], 2020. Available: https://www.who. $\mathrm{int} /$ westernpacific/news/q-a-detail/ageing-ageism

14 Hausknecht S, Clemson L, O'Loughlin K, et al. Reframing ageing in Australia, 2020. Available: https://www.age-platform.eu/publications/ reframing-ageing-australia;

15 Levy BR. Eradication of ageism requires addressing the enemy within. Gerontologist 2001;41:578-9.

16 Hausknecht S, Low L-F, O'Loughlin K, et al. Older adults' self-perceptions of aging and being older: a scoping review. Gerontologist 2020;60:e524-34.

17 Lin I, Wiles L, Waller R, et al. What does best practice care for musculoskeletal pain look like? Eleven consistent recommendations from high-quality clinical practice guidelines: systematic review. $\mathrm{Br} J$ Sports Med 2020;54:79-86.

18 Bellamy N, Buchanan WW, Goldsmith $\mathrm{CH}$, et al. Validation study of WOMAC: a health status instrument for measuring clinically important patient relevant outcomes to antirheumatic drug therapy in patients with osteoarthritis of the hip or knee. J Rheumatol 1988;15:1833-40.

19 Linton SJ, Nicholas M, MacDonald S. Development of a short form of the Örebro musculoskeletal pain screening questionnaire. Spine 2011;36:1891-5.

20 Butera KA, Lentz TA, Beneciuk JM, et al. Preliminary evaluation of a modified start back screening tool across different musculoskeletal pain conditions. Phys Ther 2016;96:1251-61. 